This article is licensed under the Creative Commons Attribution-NonCommercial 4.0 International License (CC BY-NC) (http://www.karger.com/Services/OpenAccessLicense). Usage and distribution for commercial purposes requires written permission.

\title{
Spontaneous Regression of Hepatocellular Carcinoma with Portal Vein Tumor Thrombus
}

\author{
Yudai Koya ${ }^{a}$ Tomohiro Suzuki ${ }^{b}$ Mayumi Tai ${ }^{b}$ Osamu Ichii ${ }^{b}$ \\ Nobuo Matsuhashi ${ }^{b}$ Yutaka Ejirib ${ }^{b}$ Michihiko Shibata ${ }^{a}$ Masaru Harada ${ }^{a}$ \\ aThird Department of Internal Medicine, University of Occupational and Environmental \\ Health, Kitakyushu, Japan; 'bepartment of Gastroenterology, Fukushima Rosai Hospital, \\ Iwaki, Japan
}

\section{Keywords}

Hepatocellular carcinoma - Spontaneous regression · Portal vein tumor thrombus

\section{Abstract}

An 83-year-old man underwent transcatheter arterial chemoembolization (TACE) for a 20-mm hepatocellular carcinoma (HCC) in Couinaud's segment 4. Computed tomography (CT) 4 months after TACE showed tumor thrombus in the portal vein in addition to diffuse metastases and arterioportal shunts in the left lobe. Although we performed the best supportive care, the tumor thrombus in the portal vein and tumors in the left lobe had completely disappeared on CT 16 months after the TACE. Rapidly grown portal vein tumor thrombus and arterioportal shunt might be the causes of spontaneous regression of HCC, probably associated with tumor hypoxia. 


\section{Case Reports in Gastroenterology}

Case Rep Gastroenterol 2018;12:411-419

DOI: 10.1159/00049066

(c) 2018 The Author(s). Published by S. Karger AG, Base www.karger.com/crg

Koya et al.: Spontaneous Regression of Hepatocellular Carcinoma with Portal Vein Tumor Thrombus

\section{Introduction}

Hepatocellular carcinoma (HCC) is one of the most common cancers worldwide and mostly develops in patients with chronic hepatitis B and C virus infections, although non-B, non-C HCC has been increasing in Japan $[1,2]$. Many patients are still diagnosed at the advanced stage, and their prognosis is poor, even if appropriate treatments are performed. Portal vein tumor thrombus is one of the advanced findings of HCC, and treatment options are sometimes restricted [3].

Spontaneous regression has been reported in various kinds of malignancies, including HCC $[4,5]$. Although several mechanisms of spontaneous regression of HCC have been proposed, it remains unclear. Here, we describe a rare case of spontaneous regression of HCC with massive main portal vein tumor thrombus that might be one of the causes of tumor regression.

\section{Case Report}

An 83-year-old man with hepatitis $\mathrm{C}$ virus infection was admitted to our hospital for the treatment of HCC. He had received a diagnosis of HCC and had been treated by radiofrequency ablation and transcatheter arterial chemoembolization (TACE) since the age of 74 years. He had a past medical history of hypertension, diabetes mellitus, and benign prostatic hyperplasia at 60 years of age and cerebral infarction at 72 years of age. He had no history of blood transfusion, alcohol consumption, or smoking and no family history of note. He had been receiving oral treatment with diuretics and a preparation of branched chain amino acid but not herbal medicine. Physical examination showed no symptoms suggesting severe liver damage, such as jaundice or hepatosplenomegaly. Blood tests on admission showed hemoglobin 11.9

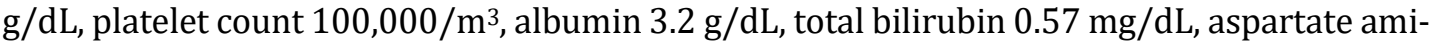
notransferase and alanine aminotransferase $28 \mathrm{IU} / \mathrm{L}$ and $46 \mathrm{IU} / \mathrm{L}$, respectively, and gamma glutamyl transpeptidase 67 IU/L. Serum alpha fetoprotein (AFP) and protein induced by vitamin K absence/antagonist-II (PIVKA-II) were $117 \mathrm{ng} / \mathrm{mL}$ and $21 \mathrm{mAU} / \mathrm{mL}$, respectively. The Child-Pugh classification belonged to category B, score 7. Serum ammonium level was within the normal range (Table 1). A contrast-enhanced computed tomography (CT) scan, which was performed 2 months before TACE, showed a tumor of $20 \mathrm{~mm}$ in diameter in Couinaud's segment 4 (S4) with the typical imaging of HCC. Then, tumor invasion into the left branch of the portal vein was not detected (Fig. 1a, b). We performed conventional TACE with Miriplatin hydrate to the S4 HCC, but lipiodol accumulation in the left branch of the portal vein was observed on a CT scan that was taken 1 week after the TACE (Fig. 1c, d). Moreover, the tumor progressed in the main portal vein after 4 months. Lipiodol in the left branch of the portal vein was completely washed out. Diffuse metastasis in the left lobe, ascites, and arterioportal shunts were newly detected by CT scan (Fig. 1e, f). Tumor markers were remarkably elevated (AFP, $631 \mathrm{ng} / \mathrm{mL}$; PIVKA-II, $501 \mathrm{mAU} / \mathrm{mL}$; Fig. 2). He did not receive any interventional treatments because of his age and the advanced stage of HCC. We subsequently attentively followed up his general conditions. Contrary to our expectations, his general condition gradually improved. A CT scan 16 months after the last TACE revealed disappearance of the thrombus of the left branch of the portal vein and atrophic change of the left lobe (Fig. 3). The tumor thrombus in the main portal vein and the tumors in the left lobe also disappeared, so we diagnosed 


\section{Case Reports in Gastroenterology}

Case Rep Gastroenterol 2018;12:411-419

DOI: $10.1159 / 00049066$

(c) 2018 The Author(s). Published by S. Karger AG, Base www.karger.com/crg

Koya et al.: Spontaneous Regression of Hepatocellular Carcinoma with Portal Vein Tumor Thrombus

spontaneous regression of HCC. There are no signs of recurrence on imaging findings or increase of tumor markers 2 years after the last TACE (Fig. 2).

\section{Discussion}

Spontaneous regression of a malignancy has been defined as a partial or complete disappearance of tumor without receiving any specific treatment [6] and is a well-established phenomenon in certain malignancies, including renal cell carcinoma, neuroblastoma, and choriocarcinoma [4]. It is a rare phenomenon with a frequency of occurrence estimated at between $1 / 60,000$ and 1/100,000 malignant cases [4]. Among these malignancies, regression of HCC appears to be a rare event. Oquiñena et al. [5] collected data from 10 randomized controlled trials involving 1,640 HCC patients and estimated the value to be $0.4 \%$.

Portal vein tumor thrombus is one of the advanced findings of HCC, and patients' prognosis is poor [3]. According to the Barcelona Clinic Liver Cancer (BCLC) staging system, which is used broadly worldwide, HCC with portal vein tumor thrombus belongs to "advanced stage," and the administration of sorafenib is recommended [7]. In Japan, a patient with HCC accompanied by a main portal vein tumor thrombus is recommended to be treated by hepatic arterial infusion chemotherapy or by the administration of sorafenib or regorafenib according to the Child-Pugh classification [8]. These treatments are sometimes effective but are harmful to the liver and accelerate the progression of pre-existing chronic liver injury. Thus, it is very difficult to survive for 2 years. In the present case, massive tumor thrombus in the main portal vein indicated a poor prognosis, but it may be one of the causes of the regression of HCC.

There are some hypotheses about the causes of spontaneous regression of HCC. Kato et al. [9] suggested that tumor hypoxia, systemic inflammatory response, and the use of herbal medicine might play an important role in the regression of HCC. Tumor hypoxia is induced by the disruption of the portal vein or feeding artery to the tumors, rapid tumor growth, large arterioportal shunt, and a shock due to massive gastrointestinal bleeding [10, 11]. Hemorrhagic shock may produce optimum conditions to regress neoplastic cells without damaging normal tissues. The neoplastic tissue is more sensitive than normal tissue to a sudden reduction of the blood and oxygen supply because of its high metabolic requirements [12]. A systemic inflammatory response includes cholangitis, sepsis, and trauma [13, 14]. Huz et al. [15] also suggested that the spontaneous regression of HCC is most commonly associated with tumor hypoxia or a systemic inflammatory response.

In the present case, the patient had not taken any herbal medicine or consumed any new drugs. There were no symptoms (e.g., fever up, abdominal pain) suggesting a systemic inflammatory response before regression of HCC. CT scan showed rapid tumor growth in the left branch to the main portal vein without formation of collateral vessels and occlusion of the artery (Fig. 1e, f). In addition, arterial blood flow and arterioportal shunt in the left lobe complementarily increased. Therefore, the massive main portal vein tumor thrombus decreased portal blood flow, and the arterioportal shunt decreased blood supply from the hepatic artery to the tumors. These disturbances of the blood circulation could have induced hypoxia of rapidly increased tumors and precipitated a tumor regression, although the hepatic artery itself was not disrupted. A delayed tumor effect of sustained release of platinum cannot be denied, but lipiodol in the left branch of the portal vein was completely washed out 4 months after the 
TACE. It is also undeniable that some occult systemic inflammatory response to HCC also precipitates a tumor regression. This is because the almost 2 years of long relapse-free survival cannot be explained by tumor hypoxia alone.

The mechanism of spontaneous regression of HCC has been studied by imaging findings and the clinical course in addition to histological and immunological findings, but it remains unclear. The accumulation of cases of spontaneous regression of HCC will contribute to the understanding of the phenomenon and is expected to give us the possibility to improve the treatment strategy for HCC.

\section{Statement of Ethics}

Consent for publication has been obtained from the patient.

\section{Disclosure Statement}

The authors have no conflict of interest.

\section{References}

1 Llovet JM, Burroughs A, Bruix J. Hepatocellular carcinoma. Lancet. 2003 Dec;362(9399):1907-17.

2 Urata Y, Yamasaki T, Saeki I, Iwai S, Kitahara M, Sawai Y, et al. Clinical characteristics and prognosis of non-B non-C hepatocellular carcinoma patients with modest alcohol consumption. Hepatol Res. 2016 Mar;46(5):434-42.

3 Llovet JM, Bustamante J, Castells A, Vilana R, Ayuso MC, Sala M, et al. Natural history of untreated nonsurgical hepatocellular carcinoma: rationale for the design and evaluation of therapeutic trials. Hepatology. 1999 Jan;29(1):62-7.

4 Cole WH. Efforts to explain spontaneous regression of cancer. J Surg Oncol. 1981;17(3):201-9.

5 Oquiñena S, Guillen-Grima F, Iñarrairaegui M, Zozaya JM, Sangro B. Spontaneous regression of hepatocellular carcinoma: a systematic review. Eur J Gastroenterol Hepatol. 2009 Mar;21(3):254-7.

6 Cole WH, Everson TC. Spontaneous regression of cancer: preliminary report. Ann Surg. 1956 Sep;144(3):366-83.

7 European Association For The Study Of The Liver; European Organisation For Research And Treatment Of Cancer. EASL-EORTC clinical practice guidelines: management of hepatocellular carcinoma. J Hepatol. 2012 Apr;56(4):908-43.

8 Kudo M, Matsui O, Izumi N, Iijima H, Kadoya M, Imai Y, et al.; Liver Cancer Study Group of Japan. JSH consensus-based clinical practice guidelines for the management of hepatocellular carcinoma: 2014 update by the Liver Cancer Study Group of Japan. Liver Cancer. 2014 Oct;3(3-4):458-68.

9 Kato H, Nakamura M, Muramatsu M, Orito E, Ueda R, Mizokami M. Spontaneous regression of hepatocellular carcinoma: two case reports and a literature review. Hepatol Res. 2004 Jul;29(3):180-90.

10 Imaoka S, Sasaki Y, Masutani S, Ishikawa O, Furukawa H, Kabuto T, et al. Necrosis of hepatocellular carcinoma caused by spontaneously arising arterial thrombus. Hepatogastroenterology. 1994 Aug;41(4):359-62.

11 Iiai T, Sato Y, Nabatame N, Yamamoto S, Makino S, Hatakeyama K. Spontaneous complete regression of hepatocellular carcinoma with portal vein tumor thrombus. Hepatogastroenterology. 2003 SepOct;50(53):1628-30.

12 Tocci G, Conte A, Guarascio P, Visco G. Spontaneous remission of hepatocellular carcinoma after massive gastrointestinal haemorrhage. BMJ. 1990 Mar;300(6725):641-2.

13 Ohta H, Sakamoto Y, Ojima H, Yamada Y, Hibi T, Takahashi Y, et al. Spontaneous regression of hepatocellular carcinoma with complete necrosis: case report. Abdom Imaging. 2005 Nov-Dec;30(6):734-7. 
Koya et al.: Spontaneous Regression of Hepatocellular Carcinoma with Portal Vein Tumor Thrombus

14 Randolph AC, Tharalson EM, Gilani N. Spontaneous regression of hepatocellular carcinoma is possible and might have implications for future therapies. Eur J Gastroenterol Hepatol. 2008 Aug;20(8):804-9.

15 Huz JI, Melis M, Sarpel U. Spontaneous regression of hepatocellular carcinoma is most often associated with tumour hypoxia or a systemic inflammatory response. HPB. 2012 Aug;14(8):500-5. 


\begin{tabular}{|c|c|c|}
\hline \multirow{3}{*}{$\begin{array}{r}\text { Case Reports in } \\
\text { Gastroenterology }\end{array}$} & \multirow{2}{*}{\multicolumn{2}{|c|}{ Case Rep Gastroenterol 2018;12:411-419 }} \\
\hline & & \\
\hline & DOI: 10.1159/000490661 & $\begin{array}{l}\text { (c) } 2018 \text { The Author(s). Published by S. Karger AG, Basel } \\
\text { www.karger.com/crg }\end{array}$ \\
\hline
\end{tabular}
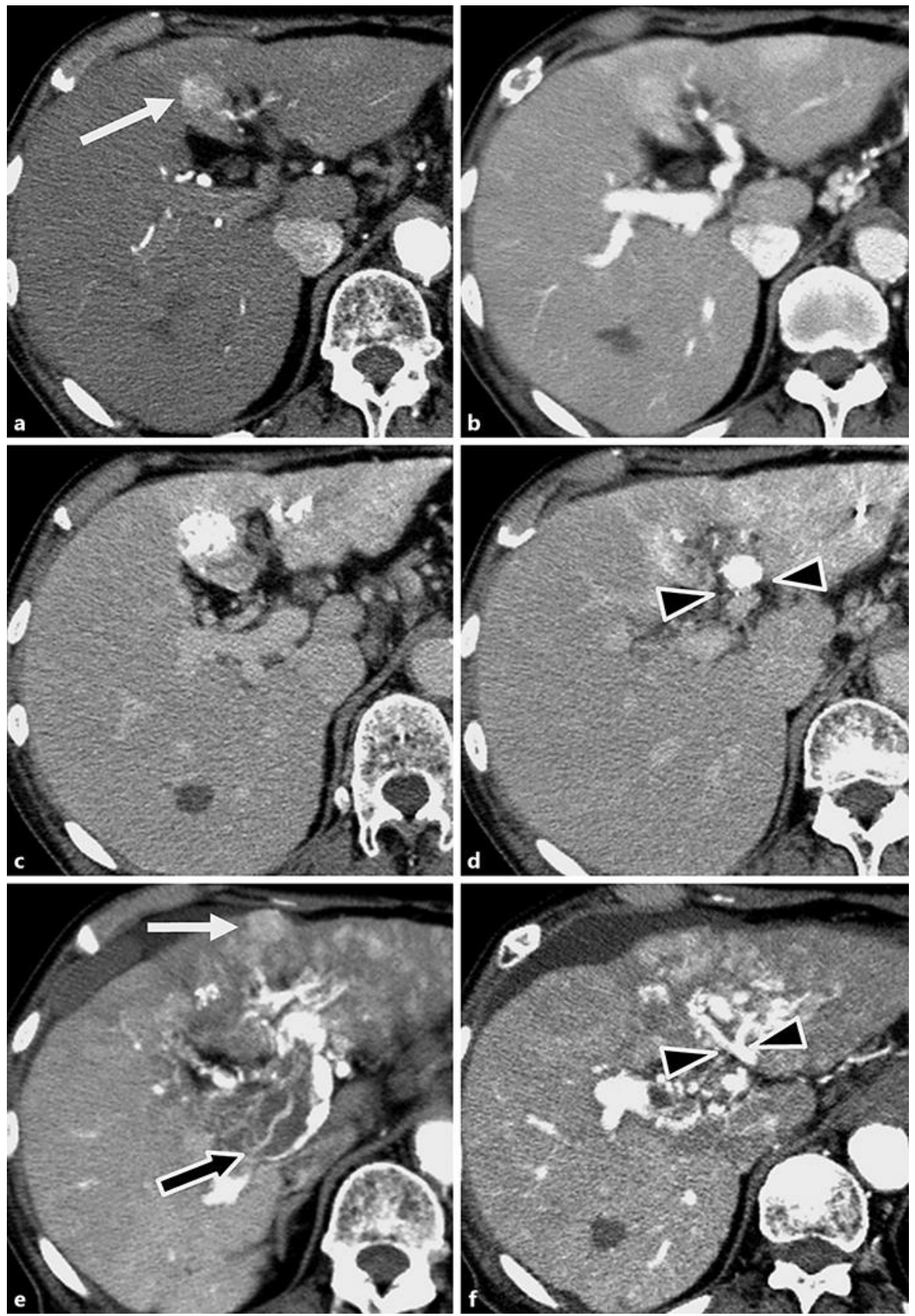
Fig. 1. Contrast-enhanced computed tomography (CT) scan performed 2 months before the transcatheter arterial chemoembolization (TACE) (a, b). A tumor $20 \mathrm{~mm}$ in size was observed in the S4 liver segment. The tumor was revealed as a high-density area in the arterial (a) (arrow) and portal (b) phase. Tumor invasion into the left branch of the portal vein was not detected. CT scan performed 1 week after conventional TACE showed lipiodol accumulations not only in the main tumor (c) but also in the left branch of the portal vein (d) (arrowheads). CT scan performed 4 months after conventional TACE showed an extensive tumor invasion into the main portal vein (e). Thread and streak sign caused by the portal vein tumor thrombus during the arterial phase was observed (e) (black arrow). Diffuse high-density area in the left lobe during the arterial phase (e) (white arrow), ascites, and arterioportal shunt were newly detected. Occlusion of the hepatic artery was not observed ( $f$ ) (arrowheads). Lipiodol in the left branch of the portal vein was completely washed out.

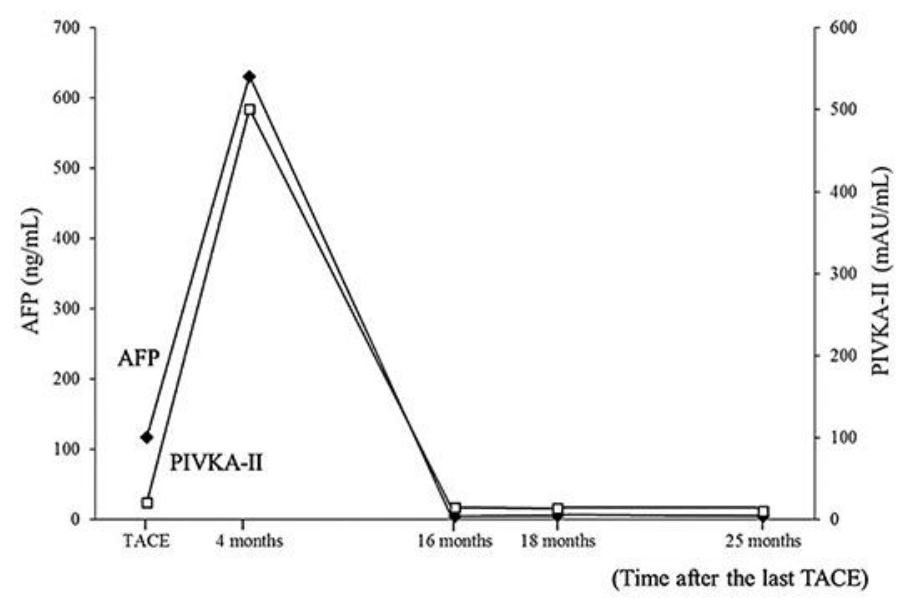

Fig. 2. Clinical course of the patient. AFP, alpha fetoprotein; PIVKA-II, protein induced by vitamin K absence/antagonist-II; TACE, transcatheter arterial chemoembolization. 


\section{Case Reports in Gastroenterology}

Case Rep Gastroenterol 2018:12:411-419

(C) 2018 The Author(s). Published by S. Karger AG, Basel www.karger.com/crg

Koya et al.: Spontaneous Regression of Hepatocellular Carcinoma with Portal Vein Tumor Thrombus
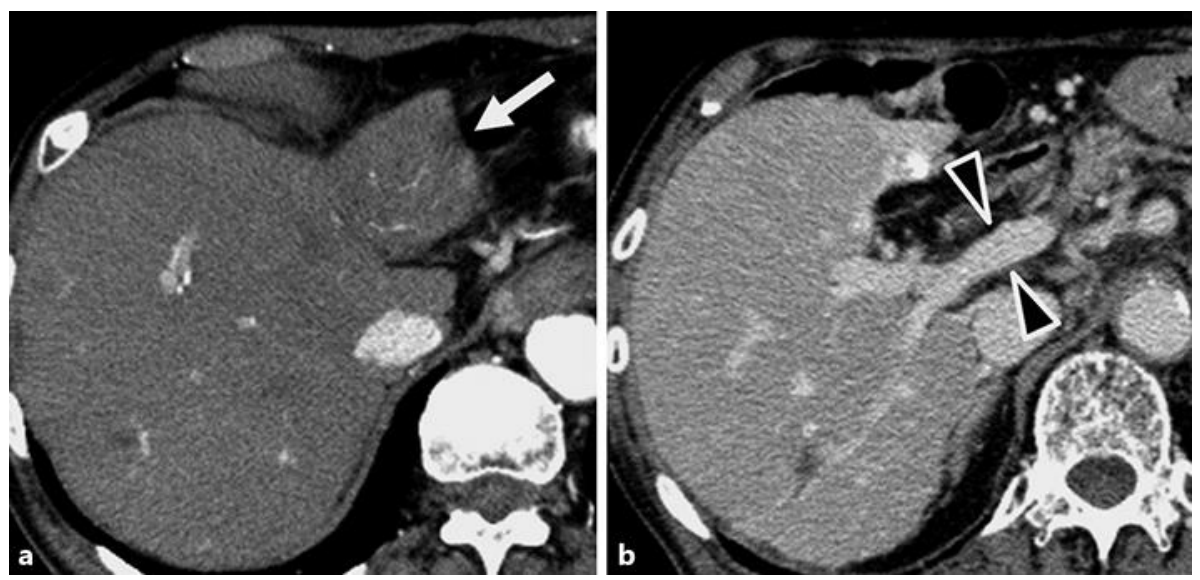

Fig. 3. Contrast-enhanced computed tomography scan performed 16 months after conventional transcatheter arterial chemoembolization showed disappearance of the diffuse high-density area in the left lobe during the arterial phase (a) (white arrow) as well as of the tumor thrombus in the main portal vein during the delayed phase (b) (arrowheads). Atrophy of the left lobe was observed. 
Table 1. Laboratory findings on admission

\begin{tabular}{|c|c|c|c|c|c|}
\hline \multicolumn{3}{|c|}{ Hematology } & \multicolumn{3}{|l|}{ Serology } \\
\hline WBC & 5,000 & $/ \mu \mathrm{L}$ & CRP & 0.09 & $\mathrm{mg} / \mathrm{dL}$ \\
\hline RBC & $378 \times 10^{4}$ & $/ \mu \mathrm{L}$ & & & \\
\hline $\mathrm{Hb}$ & 11.9 & $\mathrm{~g} / \mathrm{dL}$ & Coagulation & & \\
\hline $\mathrm{Ht}$ & 34.9 & $\%$ & PT\% & 84.2 & $\%$ \\
\hline \multirow[t]{2}{*}{ Plt } & $10 \times 10^{4}$ & $/ \mu \mathrm{L}$ & PT-INR & 1.13 & \\
\hline & & & APTT & 38 & $\mathrm{~s}$ \\
\hline \multicolumn{6}{|c|}{ Biochemistry } \\
\hline TP & 6.1 & $\mathrm{~g} / \mathrm{dL}$ & Virus markers & & \\
\hline Alb & 3.2 & $\mathrm{~g} / \mathrm{dL}$ & HBsAg & $(-)$ & \\
\hline T-bil & 0.57 & $\mathrm{mg} / \mathrm{dL}$ & $\mathrm{HBcAb}$ & $(-)$ & \\
\hline AST & 28 & $\mathrm{IU} / \mathrm{L}$ & HCVAb & $(+)$ & \\
\hline ALT & 46 & $\mathrm{IU} / \mathrm{L}$ & & & \\
\hline LDH & 129 & $\mathrm{IU} / \mathrm{L}$ & Tumor markers & & \\
\hline ALP & 327 & $\mathrm{IU} / \mathrm{L}$ & AFP & 21 & $\mathrm{ng} / \mathrm{mL}$ \\
\hline GGT & 67 & $\mathrm{IU} / \mathrm{L}$ & PIVKA-II & 117 & $\mathrm{mAU} / \mathrm{mL}$ \\
\hline BUN & 26.2 & $\mathrm{mg} / \mathrm{dL}$ & & & \\
\hline Cre & 0.85 & $\mathrm{mg} / \mathrm{dL}$ & & & \\
\hline $\mathrm{Na}$ & 137 & $\mathrm{mEq} / \mathrm{L}$ & & & \\
\hline K & 3.8 & $\mathrm{mEq} / \mathrm{L}$ & & & \\
\hline FPG & 118 & $\mathrm{mg} / \mathrm{dL}$ & & & \\
\hline $\mathrm{NH}_{3}$ & 34 & $\mu \mathrm{g} / \mathrm{dL}$ & & & \\
\hline
\end{tabular}

WBC, white blood cell; RBC, red blood cell; Hb, hemoglobin; Ht, hematocrit; Plt, platelet count; TP, total protein; Alb, albumin; T-bil, total bilirubin; AST, aspartate aminotransferase; ALT, alanine aminotransferase; LDH, lactate dehydrogenase; ALP, alkaline phosphatase; GGT, gamma glutamyl transpeptidase; BUN, blood urea nitrogen; Cre, creatinine; FPG, fasting plasma glucose; $\mathrm{NH}_{3}$, ammonia; CRP, C-reactive protein; PT, prothrombin time; APTT, activated partial thromboplastin time; HBsAg, hepatitis B surface antigen; HBcAb, hepatitis B core antibody; HCVAb, hepatitis C antibody; AFP, alpha fetoprotein; PIVKA-II, protein induced by vitamin K absence/antagonist-II. 